\title{
Business analysis for a sustainable, multi-stakeholder ecosystem for leveraging the Electronic Health Records for Clinical Research (EHR4CR) platform in Europe.
} DOI:

10.1016/j.jijmedinf.2016.11.003

\author{
Document Version \\ Accepted author manuscript
}

Link to publication record in Manchester Research Explorer

Citation for published version (APA):

Dupont, D., Beresniak, A., Sundgren, M., Schmidt, A., Ainsworth, J., Coorevits, P., Kalra, D., Dewispelaere, M., \& De Moor, G. (2017). Business analysis for a sustainable, multi-stakeholder ecosystem for leveraging the Electronic Health Records for Clinical Research (EHR4CR) platform in Europe. International journal of medical informatics, 97, 341-352. https://doi.org/10.1016/j.ijmedinf.2016.11.003

\section{Published in:}

International journal of medical informatics

\section{Citing this paper}

Please note that where the full-text provided on Manchester Research Explorer is the Author Accepted Manuscript or Proof version this may differ from the final Published version. If citing, it is advised that you check and use the publisher's definitive version.

\section{General rights}

Copyright and moral rights for the publications made accessible in the Research Explorer are retained by the authors and/or other copyright owners and it is a condition of accessing publications that users recognise and abide by the legal requirements associated with these rights.

\section{Takedown policy}

If you believe that this document breaches copyright please refer to the University of Manchester's Takedown Procedures [http://man.ac.uk/04Y6Bo] or contact uml.scholarlycommunications@manchester.ac.uk providing relevant details, so we can investigate your claim.

\section{OPEN ACCESS}




\section{Business analysis for a sustainable, multi-stakeholder ecosystem for leveraging the Electronic Health Records for Clinical Research (EHR4CR) platform in Europe}

Danielle Dupont $^{\mathrm{a}}$, Ariel Beresniak ${ }^{\mathrm{a}}$, Mats Sundgren ${ }^{\mathrm{b}}$, Andreas Schmidt ${ }^{\mathrm{c}}$, John Ainsworth ${ }^{\mathrm{d}}$, Pascal Coorevits ${ }^{\mathrm{e}}$, Dipak Kalra ${ }^{\mathrm{f}}$, Marc Dewispelaere ${ }^{\mathrm{g}}$, Georges De Moor

${ }^{a}$ Data Mining International

Route de l'Aéroport, 29-31,CP 221, Geneva, CH-1215, Switzerland

${ }^{\mathrm{b}}$ AstraZeneca R\&D

Karragatan 1, Mölndal, SE 431 83, Sweden

${ }^{c}$ F Hoffmann-La Roche Ltd (until June 2016)

Grenzacherstrasse 124, Basel, 4070, Switzerland

${ }^{\mathrm{d}}$ Centre for Health Informatics, Institute of Population Health \& Health eResearch Centre,

Farr Institute for Health Informatics Research, University of Manchester, Manchester M13 9PL, UK

${ }^{\mathrm{e}}$ Ghent University, Department of Public Health, Unit of Medical Informatics and Statistics

De Pintelaan 185, Ghent, B9000, Belgium

${ }^{\mathrm{f}}$ The European Institute for Health Records (EuroRec)

Rue du Maréchal de Lattre de Tassigny, Lille, 59000, France

${ }^{\mathrm{g}}$ MD Law

Oude Mechelse Steenweg 165, Strombeek-Bever, B1853, Belgium

\section{Corresponding Author}

\section{Dr Danielle Dupont}

Data Mining International

Route de l'Aeroport, 29-31, CP 221

CH1215, Geneva 15

Switzerland

Tel +41227993400

Fax +41227883850

ddupont@datamining-international.com 


\begin{abstract}
Introduction

The Electronic Health Records for Clinical Research (EHR4CR) technological platform has been developed to enable the trustworthy reuse of hospital electronic health records data for clinical research. The EHR4CR platform can enhance and speed up clinical research scenarios: protocol feasibility assessment, patient identification for recruitment in clinical trials, and clinical data exchange, including for reporting serious adverse events. Our objective was to seed a multi-stakeholder ecosystem to enable the scalable exploitation of the EHR4CR platform in Europe, and to assess its economic sustainability.
\end{abstract}

\title{
Materials and methods
}

Market analyses were conducted by a multidisciplinary task force to define an EHR4CR emerging ecosystem and multi-stakeholder value chain. This involved mapping stakeholder groups and defining their unmet needs, incentives, potential barriers for adopting innovative solutions, roles and interdependencies. A comprehensive business model, value propositions, and sustainability strategies were developed accordingly. Using simulation modelling (including Monte Carlo simulations) and a 5-year horizon, the potential financial outcomes of the business model were forecasted from the perspective of an EHR4CR service provider.

\section{Results}

A business ecosystem was defined to leverage the EHR4CR multi-stakeholder value chain. Value propositions were developed describing the expected benefits of EHR4CR solutions for all stakeholders. From an EHR4CR service provider's viewpoint, the 
business model simulation estimated that a profitability ratio of up to 1.8 could be achieved at year 1, with potential for growth in subsequent years depending on projected market uptake.

\section{Conclusions}

By enhancing and speeding up existing processes, EHR4CR solutions promise to transform the clinical research landscape. The ecosystem defined provides the organisational framework for optimising the value and benefits for all stakeholders involved, in a sustainable manner. Our study suggests that the exploitation of EHR4CR solutions appears profitable and sustainable in Europe, with a growth potential depending on the rates of market and hospital adoption.

Key words: ecosystem; simulation modelling; business model; value chain; electronic health records; clinical research 


\section{Introduction}

The research and development $(\mathrm{R} \& \mathrm{D})$ of new medicines has become increasingly challenging. Studies estimate that it now costs between USD 161 million and 2 billion to bring a new drug to market [1]. The main obstacles to conducting clinical trials today include high cost, lengthy time frames, administrative barriers and delays in study execution $[1,2]$. Specific challenges include assessing the feasibility of study protocols, targeting the right patient populations, identifying suitable patients for recruitment in clinical trials, and enhancing clinical data exchange. These factors explain the interest of transforming existing clinical research models so to bring innovative medicines to healthcare faster, and at lower cost $[2,3]$.

In addition, achieving success in today's economy not only demands clever innovation and highly performing technology, but agile and incentive-based business models[4]. While the term "business model" is often used, it is seldom defined explicitly[5]. Nonetheless, it has evolved considerably in the past decade with the development of taxonomies and categorizations [6-13], including the emerging concept of business model innovation [14-20]. Nowadays, business models use a system-level approach to define the manner and framework within which organisations will create, deliver and capture value[20]. In 2009, the "Business Model Canvas" was introduced as a pragmatic approach to business modelling [20]. With its nine building blocks, this systematic approach also has the merit of synthesizing and providing a general overview of the business model, which modular components can be easily updated or reorganised in response to a rapidly evolving market. By defining the organisational framework that can 
optimise full business potential, business models also assist funding and capital investment decisions.

The objective of the Electronic Health Records for Clinical Research (EHR4CR ) (http://www.ehr4cr.eu/) was to develop a scalable pan-European platform during a 5-year European research project (2011-2015) funded by the European Commission and by the European Federation of Pharmaceutical Industries and Associations (EFPIA), in the frame of the Innovative Medicines Initiative Joint Undertaking Programme (IMI-JU)[21]. More specifically, this project has developed adaptable, reusable and scalable tools and services for reusing data from electronic health records (EHR) systems for clinical research purposes. With a budget of over 16 million Euros, the EHR4CR consortium involved 34 academic and private partners (10 pharmaceutical companies), and included 11 hospital sites in France, Germany, Poland, Switzerland and the United Kingdom. It is to date one of the largest of the IMI public-private partnership in this area [21].

Importantly, the EHR4CR platform has been specially designed and engineered to unlock the contribution of health data from hospital EHR systems, in compliance with the ethical, regulatory and data protection policies and requirements of each participating country, to enable three clinical research scenarios (S): Scenario 1 (S1): Improving protocol feasibility assessments, Scenario 2 (S2): Enhancing and speeding up patient identification for recruitment in clinical trials, and Scenario 3 (S3): Optimising clinical trial data exchange, including for the reporting of severe adverse events (SAE) [21]. Detailed descriptions of the EHR4CR platform and services have been published [21, 22]. The EHR4CR platform supports distributed querying to enhance and speed up clinical trial feasibility assessments, patient identification for recruitment, and clinical 
study execution. The platform has been piloted at several large academic hospital sites across Europe to demonstrate its functionality, and the effectiveness and security of its tools and services. For this purpose, interfaces between the EHR systems and the central EHR4CR platform have been established. Semantic mapping between local terminologies and the central EHR4CR terminology has been conducted. Clinical data warehouses, compliant with the EHR4CR platform and the associated extract-transform-load processes have been designed and tested. An inventory of data elements corresponding to the most frequently occurring eligibility criteria has been defined. Approval of all data processing steps was gained in accordance with local ethical and legal regulations at each site. In particular, as the pilot sites were active in clinical research, they were able to provide exemplary local governance requirements to complement the ethical inputs referred to above. To enable wide adoption by EHR vendors, and quality assurance of the EHR4CR platform within hospitals, the project developed robust governance through accreditation and certification programmes for establishing best practices [21]. Considering that the EHR4CR platform has considerably evolved since its inception, and given its conclusive pilot testing, it has now reached the commercialization phase and is being scaled up across Europe. Since EHR4CR solutions have been designed to enhance and speed up current practices, it is predicted that they will transform clinical research environments, and generate substantial benefits for all stakeholders involved [2, 22]. Consequently, building a business ecosystem and creating sustainable business models are essential in order to successfully implement new technologies in healthcare, and to maximise the value that they can bring to health systems, healthcare organisations, care professionals, patients, care givers, citizens, and to society [23-27]. 
The main objective of our study was to design a comprehensive multi-stakeholder business ecosystem and to assess the financial sustainability of exploiting the EHR4CR platform from the perspective of an EHR4CR service provider. This paper describes the methodology used to ensure that EHR4CR solutions are deployed and exploited in a sustainable manner in Europe, and beyond.

\section{Materials and methods}

\subsection{Market analyses}

At the start of the project, a multidisciplinary Business Modelling Innovation Task Force (BMI-TF) was established to guide the design of a business model for the deployment and sustainable exploitation of the EHR4CR platform. The BMI-TF consisted of up to 15 senior representatives from EHR4CR consortium partners who were invited to participate based on their expertise and interest in business modelling (i.e. academic experts, specialists in EHR research and quality labelling, senior clinical research scientists from 6 participating pharmaceutical companies, clinical research organisations, representatives of patient organisations), including business modelling and health economics experts (designated sub-contractors to the project). Over the duration of the project, the BMI-TF met every quarter for a total 12 multidisciplinary workshops. The purpose of these workshops was to co-develop the EHR4CR ecosystem and to design and align the components of a sustainable business model (i.e. definition of the strategic plan, vision, mission and core values, multi-stakeholder value chain, value propositions adapted by stakeholder group, sustainability strategies, business model framework, and market assumptions for conducting advanced business model simulations). Before each BMI-TF workshop, an agenda and reading material were prepared and disseminated to the 
participants in order to optimise the outcomes. During the multidisciplinary workshops, strategic input was gathered through plenary and breakout sessions using small group discussions and interactive posters. After each workshop, the discussions were synthesised, and again disseminated to the BMI-TF members for further input until the next quarterly workshop. An evaluation of each workshop was conducted so to monitor progress and ensure continuing improvement. In order to gather additional market insights from the primary sponsors of clinical trials, the BMI-TF also organised a total of 3 annual strategic forums with senior clinical research pharma executives who were personally invited by each participating EHR4CR pharmaceutical partner involved in the BMI-TF. The objectives of the strategic forums were to build engagement with the executive levels of participating pharmaceutical companies (as primary sponsors of clinical trials), discuss the EHR4CR business modelling approach (including success factors and potential hurdles), and mitigate risks. Again, a detailed agenda and reading material were developed and disseminated ahead of each strategic forum. The insights gathered at each forum were synthesised in the format of executive summaries. An evaluation of each forum was also conducted with the participants.

Over the duration of the project, members of the BMI-TF reviewed the literature relevant to market analyses. They conducted semi-structured interviews with clinical research experts from the academic and health policy sectors in order to identify emerging trends, opportunities and hurdles, and to stay abreast of new developments in a rapidly changing market landscape. The strengths, weaknesses, opportunities and threats (SWOT analysis) relevant to the EHR4CR platform and solutions were identified and analysed in relation with the political, economic, societal, technological and legal aspects (PESTL analysis). 
These analyses were discussed at the BMI-TF workshops and during the strategic forums for defining the EHR4CR market landscape and business ecosystem.

In order to define the clinical research environment, the BMI-TF conducted a panEuropean multi-stakeholder e-survey at project inception [2]. The objectives of the esurvey were to investigate the perceived unmet needs, and the potential opportunities and issues related to the development and implementation of technological solutions that can improve clinical research processes. The survey questionnaire included a description of the EHR4CR project, and comprised a total of 30 multiple-choice questions investigating the following themes: i) demographic information; ii) areas for improvement in clinical research today; iii) key opportunities; iv) key challenges; v) expected benefits from the EHR4CR platform and services. The questionnaire included questions relevant to implementing EHR4CR solutions (e.g. gaps and areas that were perceived as needing improvement in clinical research, level of support for reusing EHR data for research, opportunities, level of interest and organisational readiness for implementing EHR4CR services, research domains of interest for EHR4CR solutions, perceived contributors of data, resources and services, funders and partners to consider in order to achieve research and business potential, resource availability, hurdles, and benefits of interoperable solutions).

The e-survey was conducted via an online self-administered questionnaire with European informed stakeholders from 23 European countries. The stakeholders consisted of EHR4CR partners as well as external stakeholders involved in clinical research or Information and Communication Technologies (ICT), from different relevant sectors of activity [e.g. academic centres, information technology, EHR and electronic data capture 
(EDC) system vendors, contract research organisations (CROs), clinical research sites, patient advocacy, hospitals, health agencies, pharmaceutical industry, etc.]. The e-survey was conducted by email invitation in two successive waves, the first one from June-July 2011 (with EHR4CR partners), and the second, from July-September 2011 (with external stakeholders). For this purpose, the e-survey was disseminated by consortium partners through their contact networks to stakeholders across Europe, with a request for these recipients to further invite other colleagues. Rather like the distribution of questionnaires through large mailing list databases, non-response due to a lack of interest or willingness or lack of time could not be distinguished. Overall, there were 203 respondents (78 respondents involved in the EHR4CR project and 125 who were not). Most of the respondents were from the UK $(n=39)$, Germany $(n=36)$, Belgium $(n=24)$, Sweden $(n=21)$, Switzerland $(n=14)$ and France $(n=14)$, the rest distributed across the remaining Member States. Respondents to this survey included stakeholders from academic centres $(n=42)$, pharmaceutical industry $(n=67)$, IT providers and EHR and EDC system vendors $(n=38)$, clinical research organisations and sites $(n=28)$, patient advocacy groups $(n=4)$, health agencies $(n=4)$, and other relevant sectors $(n=20)$. Most respondents had an experience of more than 15 years within their sector of activity, providing domainspecific expertise and proficiency. In October 2011, the survey responses from each wave were analysed separately by a senior statistician from the Centre for Health Informatics \& Multiprofessional Education (CHIME), University College London. The analysis highlighted the main areas for improvement in clinical research today, key opportunities and challenges, and the expected benefits from EHR4CR services for all stakeholders. Using relevant statistical tests, the results from both waves [2] were also compared to 
show potential differences. The e-survey findings (which were used to guide the strategic development of the business model framework and its core components) are summarised in the Results Section.

\subsection{Vision, mission and core values}

Using the results of the pan-European $e$-survey and market analyses, the BMI-TF developed a strategic plan using a systematic approach [28-30]. As a first step, the BMI-TF defined the EHR4CR vision, mission and core values. The vision statement is future-based and consists of the long term goal to be achieved. It is a declaration of an organisation's objective which defines the desired future state in terms of its strategic direction [31-33]. Because the vision is the inspiration providing the strategic planning framework, it is formulated as an inspiring pledge of what an organisation wants to become. In order to achieve the vision, the mission statement describes the purpose of the organisation $[31,33,34]$, while the core values represent the principles by which the mission is to be conducted. As values are often culture-specific, they also guide an organisation's strategic priorities and decisions [33].

\subsection{Business ecosystem}

For ensuring the deployment of the EHR4CR platform and solutions, the BMI-TF envisioned a free market environment involving multiple interdependent stakeholders contributing to creating, delivering and capturing value in a scalable and sustainable manner. In order to optimise stakeholders' interests, a framework fostering interdependencies was defined [35], taking into account market dynamics, industry drivers, and sustainability strategies. In order to provide governance and to act as a 
catalyst of this new business ecosystem, the BMI-TF proposed the creation of an independent institute. The different components of the business ecosystem are described in the Results Section.

\subsection{Multi-stakeholder value chain}

The BMI-TF developed a multi-stakeholder value chain in order to leverage the interdependencies. For this purpose, the BMI-TF identified key stakeholder groups and segmented them into four categories: i) Providers ii) Funders iii) Users, and iv) Beneficiaries of EHR4CR solutions. This functional categorisation contributed to structuring the environment for optimising value. The EHR4CR value chain is described in the Results Section.

\subsection{Customised value propositions}

Because they describe the benefits that new products or services provide to customers and stakeholders, value propositions are central to business models. The BMI-TF developed value propositions and adapted them in relation to the unmet needs identified by the market analyses. These descriptive value propositions are presented in the Results Section. Where relevant, the value propositions were substantiated with quantitative assessments using relevant stakeholders' perspectives.

\subsection{Business model and implementation roadmap}

By definition, a business model describes the organisational framework and the processes involved in optimising the value that can be created, delivered and captured from leveraging innovative products, technologies and services [20]. Using the perspective of the EHR4CR service provider, the BMI-TF developed a business model canvas [20] by 
populating nine building blocks: the customer segments of the EHR4CR service providers, the type of customer relationships and channels to be developed, the activities, resources and partnerships to be implemented and deployed, and the cost structure and revenue streams that will enable delivering the value propositions to the customer segments, in a sustainable manner. The financial scheme was established considering an EHR4CR service provider's estimated expenses and revenue streams. The expenses were estimated in relation to the scope of activities to be implemented (i.e. operational costs, salaries, overhead, commercial operations, data access fees, domain-specific experts, etc.), as well as the revenue streams (i.e. annual subscriptions for connecting clinical trials sponsors to the EHR4CR platform, fees per EHR4CR service, and potential licensing and consultative fees). These aspects were defined, discussed and populated by the BMI-TF considering the scope of the EHR4CR ecosystem, the multi-stakeholder value chain, the market analyses, the business intelligence gathered during the strategic forums, and the perceived success factors. An implementation roadmap was also developed to leverage the sustainability strategies that would optimise the delivery of the EHR4CR benefits to stakeholders. The components of the business model developed from the perspective of the EHR4CR service provider is summarised in the Results Section.

\subsection{Business model simulation}

The scope of the EHR4CR target market was defined considering the estimated number of commercially and non-commercially sponsored Phase II, III, IV clinical trials (CTs) to be conducted in Europe over 5 years by the following clinical trials sponsors' segments: Pharmaceutical Research Organisations (PROs) and their CROs, as well as academic 
Clinical Research Units (CRUs). Based on the European market landscape defined, the expected numbers of PROs, CROs and CRUs were estimated. All estimates are provided in the Results Section.

The BMI-TF considered that EHR4CR solutions would be implemented in up to 5-10\% of Phase II, III, IV CTs to be conducted in Europe over 5 years, with increasing market uptakes for each EHR4CR scenario in a non-mutually exclusive fashion. In order to forecast the financial outcomes, the business model simulation used market assumptions validated by the BMI-TF, including the categories of expenses and revenues considered for an EHR4CR service provider. The EHR4CR service providers' yearly expenses were estimated by defining the estimated operational costs (minimum and maximum value ranges over a 5-year horizon) for each of the cost categories defined.

The potential annual revenues for an EHR4CR service provider were calculated considering all revenue streams, including the EHR4CR fees for service (i.e. for enhancing and speeding up protocol assessment, patient identification for recruitment, and clinical data exchange including SAE reporting). Given the pre-launch context, EHR4CR fees for service were estimated as willingness-to-pay (WTP) ranges defined by 6 participating EFPIA partners (2012) for each EHR4CR scenario, based on their business intelligence and perceived benefits of the EHR4CR platform. Those WTP assumptions were defined as small increasing percentage ranges of the average clinical trial per-patient costs across therapeutic areas, also considering the average estimated number of patients per CT. The revenues per service provider were then estimated considering the projected minimum and maximum number of Phase II, III, IV CTs for each EHR4CR service based on the potential market uptake of EHR4CR solutions in 
Europe. Then, the profitability ratio (estimated revenues divided by the estimated expenses) was derived using simulation modelling.

In order to manage uncertainty, probabilistic sensitivity analyses (10,000 Monte Carlo simulations[36]) were conducted taking into account data variance across the distribution of all parameters (i.e. between the minimum and maximum values provided) for the expenses and revenues estimated per EHR4CR service provider.

\section{Results}

\subsection{Market analyses}

The e-survey results confirmed the gaps and areas for improving today's clinical research processes, as well as the benefits and research opportunities that could be realised with the EHR4CR platform [2]. The clinical research processes identified as needing most improvement included: patient identification for recruitment in clinical trials (70\% of respondents), time needed to conduct clinical trials (59\%), clinical research high costs and workload (54\%), and protocol feasibility assessment (50\%). The results from both waves showed a high degree of consistency across most aspects surveyed. In addition, the vast majority (74\%) of respondents expressed interest in a value-driven EHR4CR platform rather than in a cost-saving platform, meaning that they were interested in valueadded (i.e. providing tangible benefits) and cost-effective solutions[2].

\subsection{EHR4CR vision, mission and core values}

Considering that the EHR4CR IMI project had declared the ambition of developing and establishing a scalable pan-European technological platform and service framework to enable the trustworthy re-use of patient-level data from hospital EHRs for clinical 
research, a strategic plan was developed by the BMI-TF, including the definition of the EHR4CR vision, mission and core values (Table 1).

Table 1. EHR4CR Vision, Mission and Core Values

\begin{tabular}{|l|l|l|}
\hline $\begin{array}{l}\text { Vision } \\
\text { Statement }\end{array}$ & - $\begin{array}{l}\text { To be the trusted gateway to eHealth information for research and knowledge } \\
\text { discovery to transform healthcare worldwide. }\end{array}$ \\
\hline $\begin{array}{l}\text { Mission } \\
\text { Statement }\end{array}$ & - $\begin{array}{l}\text { Delivering sustainable value-added solutions for the trustworthy re-use of } \\
\text { eHealth data and information to improve global clinical research. }\end{array}$ \\
\hline $\begin{array}{l}\text { Core } \\
\text { Values }\end{array}$ & - $\begin{array}{l}\text { Provide flexible, scalable and interoperable solutions } \\
\text { Ensure full compliance with relevant ethical, legal, regulatory, and privacy } \\
\text { protection standards and policies }\end{array}$ \\
& $\begin{array}{l}\text { Deliver innovative, customer-focused and sustainable value-added services } \\
\text { Optimise healthcare connectivity by enabling adoption, collaboration, } \\
\text { accountability and transparency. }\end{array}$ \\
\hline
\end{tabular}

In order to build awareness and stakeholder engagement, educational material was developed and dissemination strategies were deployed throughout the duration of the project.

\subsection{EHR4CR business ecosystem}

The EHR4CR business ecosystem is based on the organisational framework described in

Fig. 1, and involves the following actors: i) Data Providers (DP), i.e. hospitals to contribute anonymised hospital-based EHR health data for research purposes ii) Service Providers (SP) to enable and deliver EHR4CR services to iii) Service Users (SU) (e.g. pharmaceutical industry, CRUs, CROs, etc.) to implement EHR4CR solutions for enhancing and speeding up clinical research processes (i.e. protocol feasibility assessment, patient identification for recruitment, and clinical data exchange). In this context, EHR4CR service providers will be new service entities, or existing organisations interested in providing EHR-enabled solutions for clinical research (e.g. trusted-third parties, CROs, and other vendors of the defined ecosystem). The business model assumes 
that new business opportunities and potential alliances will emerge from this open market in which commercial interests will be stimulated, and where cooperation and competition (“coopetition") will coexist. As stated above, the EHR4CR solutions are now being commercialised and will be provided initially through InSite ${ }^{\circledR}$, the first EHR4CR service platform (https://www.insiteplatform.com).

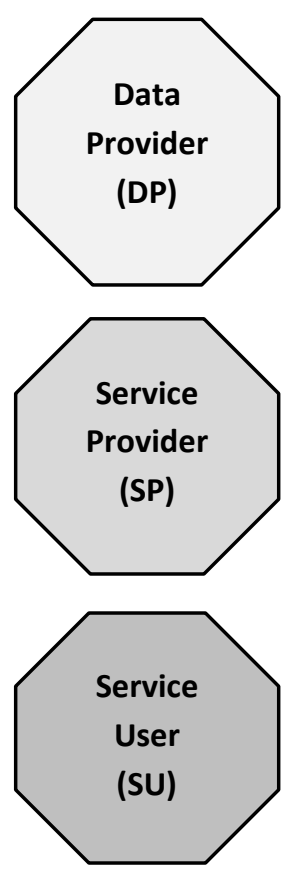

An organisation that contributes data for EHRCR e.g. hospital

An organisation that provides EHR4CR services to Service Users EHRCR e.g. hospital

An organisation that uses EHR4CR services such as a pharmaceutical company or an academic institution

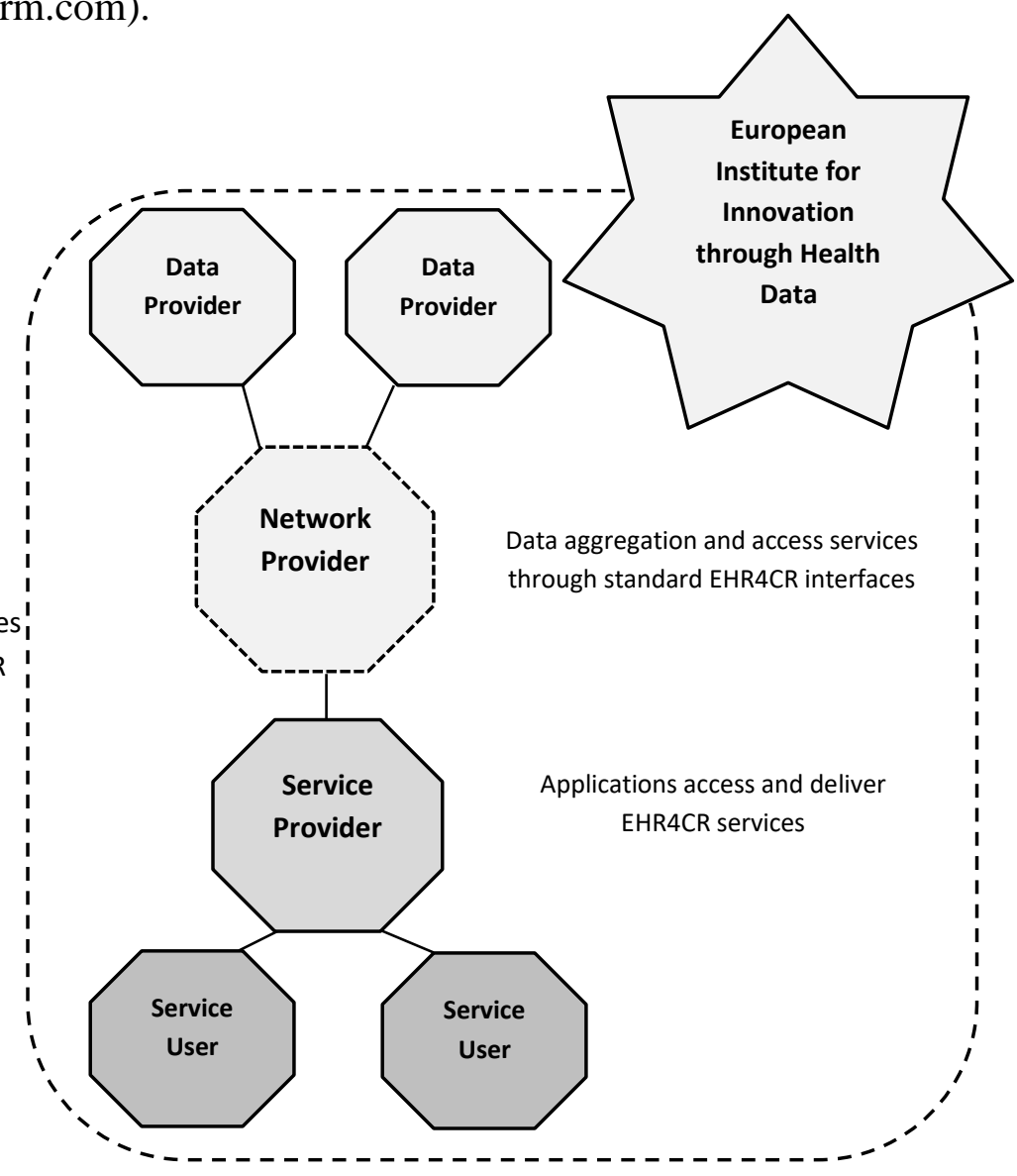

Fig.1 EHR4CR Scalable Business Ecosystem

As described above and illustrated in Fig.1, the ecosystem involves the "European Institute for Innovation through Health Data (“iHD”)[37] (http://www.i-hd.eu/), a nonprofit independent organisation created to stimulate R\&D opportunities, to provide governance for the research uses of health data, and to oversee accreditation and certification services for ensuring highest quality standards (i.e. data quality, interoperability, data privacy, ethics, etc.). Considering the scalable deployment of the 
service platform, further stakeholders (e.g. network providers) are expected to join this dynamic ecosystem in the future, in order to expand its scope, including at the global level.

\subsection{EHR4CR multi-stakeholder value chain}

The market analyses conducted have emphasised the importance of developing a business model that addresses multi-stakeholders' mutual interests. Contrary to a one-sided market (where suppliers and customers are independent from each other), multi-sided markets link two or more distinct but interdependent groups of stakeholders. These are proliferating today as modern information technology creates more opportunities for organising complex markets and business platforms [38, 39]. As business models are constructed by integrating interaction patterns and value chains [40], the value chain developed by the BMI-TF and described in Fig. 2 illustrates that the EHR4CR ecosystem consists of a market where distinct groups of stakeholders provide each other with "network" (value chain) benefits (i.e. SP, DP, clinical trial sponsors, and citizens). In a traditional value chain, value moves from left to right. To the left of the organisation is cost; to the right is revenue. In multi-sided networks, cost and revenue are both to the left and the right[41]. As illustrated in Fig. 2, the value chain shows the interdependencies amongst stakeholders that contribute to creating, delivering, and optimising value across the EHR4CR network defined. 


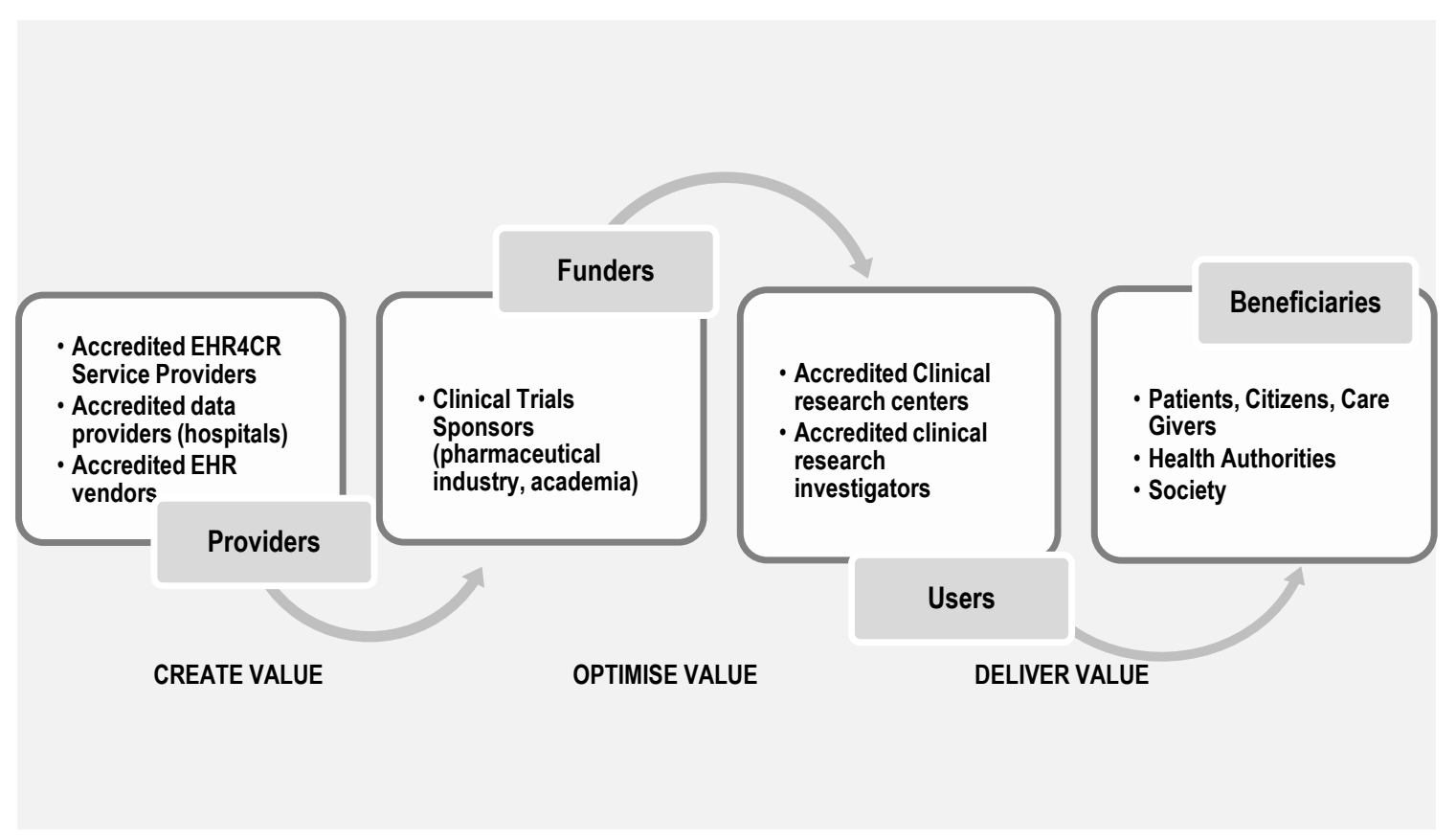

Fig. 2 Optimising the EHR4CR Multi-Stakeholder Value Chain

\subsection{EHR4CR customised value propositions}

The EHR4CR value propositions developed to reflect the unmet needs of different stakeholder segments are summarised in Table 2. These value propositions proved important during the development and refinement of the EHR4CR technical approach and business model as they helped to confirm the expected benefits, and the success factors that would be needed by each stakeholder to realise them. 
Table 2: EHR4CR value propositions adapted by stakeholder group

\begin{tabular}{|c|c|}
\hline Stakeholder Segment & Expected Benefits \\
\hline Service Providers & $\begin{array}{l}\text { Enable seamless technological solutions for the research use of } \\
\text { EHR-health data } \\
\text { - Build and grow a profitable and sustainable business landscape } \\
\text { - Leverage new business opportunities }\end{array}$ \\
\hline $\begin{array}{l}\text { Clinical Trial Sponsors } \\
\text { (pharmaceutical } \\
\text { industry, CROs, CRUs) }\end{array}$ & $\begin{array}{l}\text { - } \text { Enhance the efficiency of clinical trial processes } \\
\text { - } \text { Reduce the time and costs of bringing new drugs to market } \\
\text { - Generate added value }\end{array}$ \\
\hline $\begin{array}{l}\text { Hospitals, Clinical } \\
\text { Research Centers, } \\
\text { Clinical Investigators }\end{array}$ & $\begin{array}{l}\text { - Participate in more clinical research programmes } \\
\text { - } \text { Improve health data quality } \\
\text { - } \text { Enhance health care pathways } \\
\text { - Increase research activities and revenues }\end{array}$ \\
\hline $\begin{array}{l}\text { ICT Industry } \\
\text { (EHR/EDC vendors) }\end{array}$ & $\begin{array}{l}\text { Provide EHR solutions that will support interoperable clinical } \\
\text { data capture and exchange } \\
\text { - Develop business channels } \\
\text { - Grow existing market }\end{array}$ \\
\hline Patients & $\begin{array}{l}\text { - Benefit from more patient-centered clinical trials } \\
\text { - Gain access to safe and effective medicines, towards improving } \\
\text { health outcomes and safeguarding patient safety }\end{array}$ \\
\hline $\begin{array}{l}\text { Regulatory Bodies, } \\
\text { Health Technology } \\
\text { Assessors }\end{array}$ & $\begin{array}{l}\text { - Generate high quality clinical efficacy, safety, cost- } \\
\text { effectiveness and comparative effectiveness evidence } \\
\text { - Support decision-making (marketing authorisation, } \\
\text { reimbursement recommendations) }\end{array}$ \\
\hline $\begin{array}{l}\text { Health Authorities, } \\
\text { Health Care Planners, } \\
\text { Governments }\end{array}$ & $\begin{array}{l}\text { Enhance health policies, public health programmes and } \\
\text { decisions for optimising health care delivery and patient } \\
\text { outcomes }\end{array}$ \\
\hline $\begin{array}{l}\text { European Clinical } \\
\text { Research Market }\end{array}$ & - Attract more R\&D investments in Europe \\
\hline
\end{tabular}

\subsection{EHR4CR business model and implementation roadmap}

Using best practices [20], the business model summarised in the Appendix was developed using the perspective of the EHR4CR service provider to establish an organisational business environment for enabling the deployment and sustainable exploitation of EHR4CR services. The EHR4CR business model highlights which customer segments the EHR4CR service providers should focus on, how they will be 
reached, through which channels, for providing which services, and how this will be accomplished by leveraging key activities, resources and partnerships, and under which financial scheme. In order to optimise the adoption of new technologies and commercial success, the development of an adoption roadmap contributes to: $i$ ) Planning the platform; ii) Establishing strategic partnerships; iii) Engaging the community for achieving full business potential.

\subsection{Business model simulation}

In order to assess the economic sustainability of the business model, the number of commercially sponsored and non-commercially sponsored Phase II, III and IV CTs to be conducted in Europe over the next 5 years was calculated. Multiple data sources were investigated. At the time of model development, the BMI-TF selected the EMA EudraCT 2012[42] and its retrospective dataset (2007-2011) as baseline values. The worldwide average per-patient costs (USD) per Phase II, III and IV CTs across therapeutic areas under current practices were used as proxy (Table 3).

Table 3: Estimated yearly number of commercially and non-commercially sponsored Phase II, III, IV CTs in Europe, and estimated average worldwide per-patient costs (USD) across therapeutic areas

\begin{tabular}{|c|c|c|c|}
\hline $\begin{array}{c}\text { Clinical Trial } \\
\text { (CT) Phase }\end{array}$ & $\begin{array}{c}\text { Number of CTs in } \\
\text { Europe }^{\S} \mathbf{( 2 0 1 2 )}\end{array}$ & $\begin{array}{c}\text { Retrospective Annual } \\
\text { Ranges } \\
(\mathbf{2 0 0 7 - 2 0 1 1 )}\end{array}$ & $\begin{array}{c}\text { Average worldwide per- } \\
\text { patient costs (USD) per } \\
\text { clinical trial phase across } \\
\text { therapeutic areas }\end{array}$ \\
\hline II & 1,263 & $1,173-1,498$ & 36,070 \\
\hline III & 926 & $817-1,148$ & 47,609 \\
\hline IV & 729 & $637-908$ & 17,042 \\
\hline
\end{tabular}

Source: $\S E$ EudraCT 2012 (baseline), including commercially sponsored (PRO/CRO) and non-commercially sponsored clinical trials (CTs) (universities, hospitals, public organisations)

†: Cutting Edge Report 2011 
The estimated per-patient costs were obtained from the Cutting Edge database (http://www.cuttingedgeinfo.com) based on queries generated during the first quarter of 2013.These estimated costs include: patient recruitment, vendor fees, technology, site retention, data cleaning, stats analysis, reports, patient retention costs. As the average worldwide per-patient costs vary across therapeutic areas (oncology being reported as the most costly) and geographic boundaries, and considering volatile exchange rates over the duration of the project, our baseline assumptions used a conservative average per-patient cost of 10,000 euros, and an estimated average of 250-500 patients/CT for the purpose of the business model simulation. In order to estimate the potential fees for service, our model then applied different ranges of increasing percentages to the per-patient costs baseline estimate, multiplied by the estimated average range of patients per CT. The business model simulation then calculated the profitability ratio taking into account potential variations by calculating the distribution of all potential values, across all the ranges provided, for all the parameters used to populate the model.

In order to forecast the number of CTs that would be conducted in the next 5 years, the BMI-TF conducted a confidential survey with 6 pharmaceutical companies involved in the EHR4CR project. Their individual estimated annual projections were expressed as expected percentages of increase, decrease or no significant change in the number of Phase II, III and IV CTs to be conducted in Europe in the next 5 years (2014-2018). These percentages were defined as minimum and maximum values which were then computed and applied to the yearly estimated number of 2012 CTs in order to derive 5year cumulative forecasted ranges (Table 4). 
Table 4: Estimated ranges of commercially and non-commercially sponsored Phase II, III, IV CTs in Europe

\begin{tabular}{|c|c|c|}
\hline Type & $\begin{array}{c}\text { Estimated annual number of } \\
\text { Phase II, III, IV CTs } \\
\text { (estimated ranges) }^{\S}\end{array}$ & $\begin{array}{c}\text { Estimated 5-Year } \\
\text { Cumulative Forecast } \\
\text { (estimated ranges) }^{\dagger}\end{array}$ \\
\hline Commercial & $1,000-1,500$ & $4,900-9,285$ \\
\hline Non-commercial & $1,580-1,680$ & $7,740-10,395$ \\
\hline Total & $2,580-3,180$ & $12,640-19,680$ \\
\hline
\end{tabular}

Source: \$EudraCT 2012 (based on estimated baseline)

$\uparrow$ Ranges derived using pharmaceutical industry 5-year projections (2014-2018); Clinical Trials (CT)

The EudraCT 2014 database statistics were later compared with the projected values, confirming the accuracy of the BMI-TF estimations. For the purpose of this study, the BMI-TF defined Phase IV CTs as well-controlled post-registration clinical trials, targeting special populations, or comparing a new intervention with current treatments (standard of care). Hence, Phase IV CTs excluded non-interventional observational studies for assessing comparative effectiveness in real-word contexts. Given an increasing demand for real-world evidence, it is however expected that studies conducted in real-world contexts would also benefit from the EHR4CR platform in the future.

As indicated in Table 5, the BMI-TF estimated that a total of 5-15 EHR4CR service providers could collectively achieve up to 5-10\% of market shares of Phase II,III,IV CTs to be conducted in Europe over 5 years. The potential 5-year market size (number of potential CTs) per EHR4CR service provider was estimated by applying the EHR4CR market shares on the estimated number of Phase II, III, IV CTs that could use EHR4CR services, divided by the estimated number of accredited service providers. 
Table 5: EHR4CR Business Model Assumptions

\begin{tabular}{|c|c|}
\hline Assumption & Estimated Cumulative 5-year Ranges \\
\hline $\begin{array}{c}\text { Estimated number of EHR4CR } \\
\text { Service Providers }\end{array}$ & $5-15$ \\
\hline $\begin{array}{c}\text { EHR4CR estimated 5-year } \\
\text { total CT market shares }\end{array}$ & $5-10 \%$ \\
\hline $\begin{array}{c}\text { Estimated number of Phase II, III, IV CTs } \\
\text { for EHR4CR solutions }\end{array}$ & $632-1,968^{\dagger}$ \\
\hline $\begin{array}{c}\text { Total 5-year (min. and max.) estimated } \\
\text { number of Phase II, III, IV CTs per } \\
\text { EHR4CR Service Provider }\end{array}$ & $42-394$ \\
\hline
\end{tabular}

\$Ranges established by the BMI-TF Derived from applying 5-10\% to the estimated 5-year forecasted ranges (Table 4) Clinical Trials $(C T)$

The expenses and revenues estimated for an EHR4CR service provider were calculated for each category based on the assumptions defined by the BMI-TF. Considering a 5-year horizon, Table 6 summarises the underlying assumptions and the potential expenses and revenues (5 years annualised). 
Table 6: Estimated expenses and revenues annualised per EHR4CR service provider

\begin{tabular}{|c|c|c|c|}
\hline $\begin{array}{c}\text { Categories of } \\
\text { Expenses } \\
\text { Assumptions } \$ \\
\end{array}$ & $\begin{array}{c}\text { Potential Expenses } \\
\text { Annualised } \\
\text { Min-Max }(\mathrm{K} €) \\
\end{array}$ & $\begin{array}{l}\text { Revenue Streams } \\
\text { Assumptions }^{\S}\end{array}$ & $\begin{array}{c}\text { Potential Revenues } \\
\text { Annualised } \\
\text { Min-Max (K€) } \\
\end{array}$ \\
\hline $\begin{array}{l}\text { Human Resources } \\
\text { (salaries, benefits etc.) }\end{array}$ & $1,130-2,225$ & $\begin{array}{l}\text { Connecting to the EHR4CR } \\
\text { Platform } \\
\text { - Annual subscription fees per } \\
\text { clinical trial (CT) sponsor }\end{array}$ & $306-1,670$ \\
\hline Outsourcing & $300-400$ & 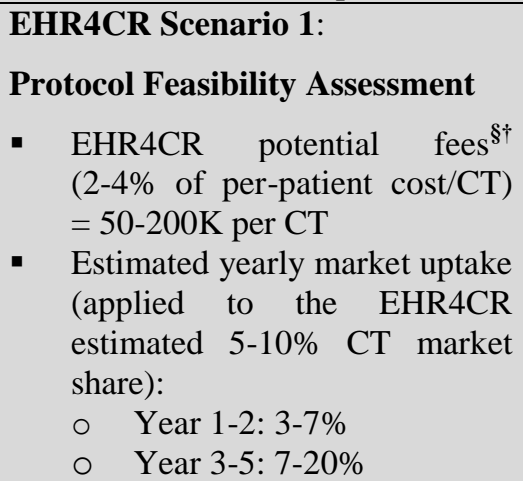 & $50-4,320$ \\
\hline $\begin{array}{l}\text { Telecommunications } \\
\text { and Equipment }\end{array}$ & $35-60$ & $\begin{array}{l}\text { EHR4CR Scenario 2: } \\
\text { Patient Identification for } \\
\text { Recruitment } \\
\text { - EHR4CR potential fees }{ }^{8 \dagger} \\
\text { (3-5\% of per-patient cost/CT) } \\
\text { =75-250K per CT } \\
\text { - Estimated yearly market uptake } \\
\text { (applied to the EHR4CR } \\
\text { estimated 5-10\% CT market } \\
\text { share): } \\
\text { O Year 1-2: } 15-30 \% \\
\text { O Year 3-5: } 30-60 \%\end{array}$ & $270-17,740$ \\
\hline IT Infrastructure & $35-60$ & \multirow{8}{*}{$\begin{array}{l}\text { EHR4CR Scenario 3: } \\
\text { Clinical Data Exchange and SAE } \\
\text { Reporting } \\
\text { - EHR4CR potential fees } \text { S }^{\S \dagger} \\
\text { (5-10\% of per-patient cost/CT) } \\
\text { = 125-500K per CT } \\
\text { Estimated yearly market uptake } \\
\text { (applied to the EHR4CR } \\
\text { estimated 5-10\% CT market } \\
\text { share): } \\
\text { O Year 1-2: } 1-5 \% \\
0 \text { Year 3-5: 5-30\% }\end{array}$} & \multirow[t]{8}{*}{$82.5-14,490$} \\
\hline Marketing & 150 & & \\
\hline $\begin{array}{l}\text { Operating Fees } \\
\text { (connecting data } \\
\text { providers, data access } \\
\text { fees, certification, } \\
\text { accreditation, privacy } \\
\text { protection, etc). }\end{array}$ & $308-10,268$ & & \\
\hline Overhead & $190-200$ & & \\
\hline Office Supplies & $20-30$ & & \\
\hline $\begin{array}{l}\text { Juridical, Contractual, } \\
\text { Insurance }\end{array}$ & $135-270$ & & \\
\hline $\begin{array}{l}\text { Licensing fees } \\
\text { (terminology, } \\
\text { codes,etc.) }\end{array}$ & $75-150$ & & \\
\hline Travel Expenses & $100-150$ & & \\
\hline
\end{tabular}

$\dagger$ : Expressed as willingness to pay ranges 
As reported in Table 6, the EHR4CR estimated fees for services were derived for each EHR4CR scenario using the approach described in the Methods and materials section [i.e. by applying the WTP assumptions defined by EFPIA partners as marginal increasing percentage ranges of the average worldwide per-patient costs per CT across therapeutic areas (estimated at 10,000 euros/patient), multiplied by the estimated average range of patients per CT (250-500), yielding potential EHR4CR fees of 50-200K €/CT for Scenario 1; 75-250K €/CT for Scenario 2; and 125-500K €/CT for Scenario 3]. The potential revenues per service provider were derived considering the projected minimum and maximum number of CTs for each EHR4CR scenario. The potential number of Phase II, III, IV CTs for each EHR4CR service was derived by applying increasing market uptake assumptions to the EHR4CR scalable 5-year CT market shares (5-10\%). Using simulation modelling, the potential financial outcomes were estimated per service provider for exploiting the EHR4CR platform. The business simulation calculated the potential revenues assuming that the market uptake objectives set for each EHR4CR scenario would be achieved (Table 6). The potential revenues for exploiting the EHR4CR platform were estimated allowing service bundles between EHR4CR scenarios within the ranges of the market uptake objectives set for each, so that EHR4CR scenarios could potentially be used individually, in combination, or sequentially for a given CT (non-mutually exclusive). All potential values were screened by carrying out probabilistic sensitivity analyses according to specific distribution shapes. Using a random number generator programmed in D-Script language, 10'000 Monte Carlo simulations were performed on uniform or normal distribution shapes, depending on the type of data collected. The results were generated with their distribution parameters, as reported in 
Table 7 (simulation summary of estimated expenses and potential revenues per service provider at Year 1), and as illustrated in Fig. 3 and Fig 4 (cumulative distribution curves).

Table 7. Distribution parameters of estimated expenses and revenues per service provider -Year 1

\begin{tabular}{|l|c|c|}
\hline \multicolumn{1}{|c|}{ Measure } & $\begin{array}{c}\text { Estimated expenses } \\
\text { (Year 1) }\end{array}$ & $\begin{array}{c}\text { Estimated revenues } \\
\text { (Year 1) }\end{array}$ \\
\hline Observations & 10 ’000 & 10 ’000 \\
\hline Mean & 5018592.77 & 8917810.45 \\
\hline Standard Deviation & 2858952.59 & 3035781.48 \\
\hline Variance & 8173609891584.24 & 9215969197008.34 \\
\hline Minimum & 103927.82 & 1372410.36 \\
\hline $5^{\text {th }}$ Percentile & 604523.74 & 4000195.83 \\
\hline Median & 5002881.38 & 8925860.44 \\
\hline $95^{\text {th }}$ Percentile & 9514040.69 & 13791553.44 \\
\hline Maximum & 10002821.09 & 16418109.81 \\
\hline
\end{tabular}

\section{Cumulative Distribution}

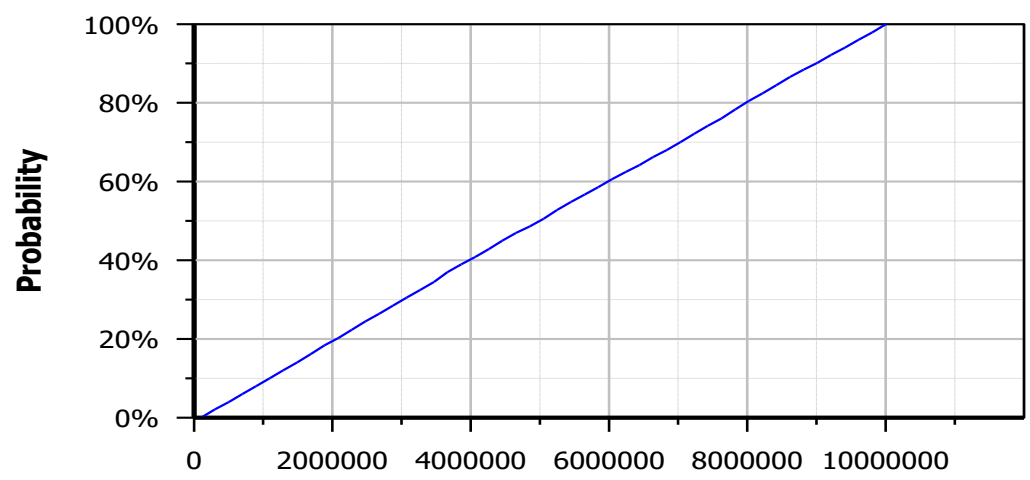

Fig.3 Cumulative distribution of estimated expenses per service provider - Year 1

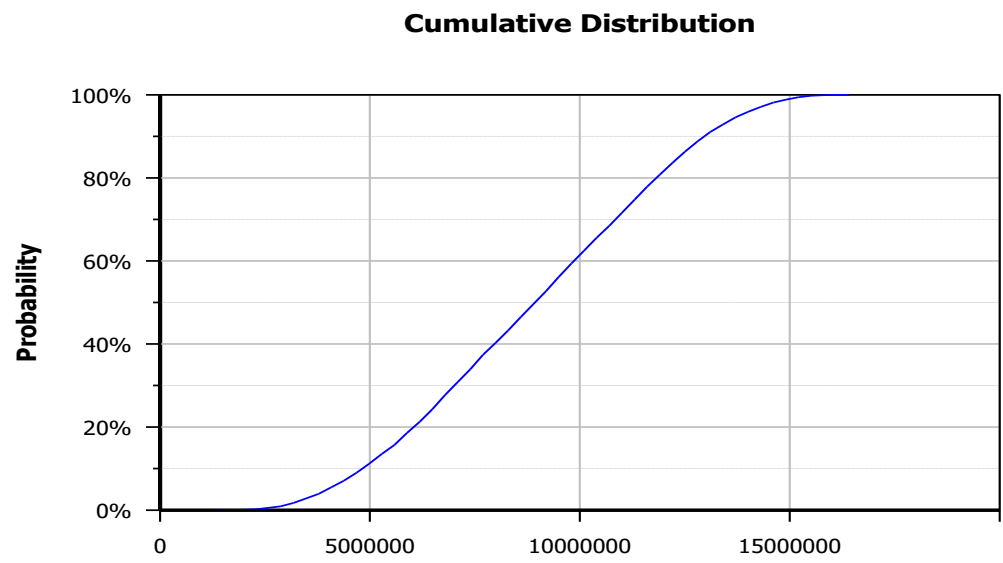

Fig.4 Cumulative distribution of estimated revenues per service provider - Year 1 
Assuming that the EHR4CR platform is fully operational and optimally deployed at time of launch, the results generated by the probabilistic sensitivity analyses suggest that an average profitability ratio (potential revenues divided by the estimated expenses) of up to 1.8 could be achieved as of Year 1, with a growth potential in the subsequent years being dependent on the EHR4CR projected market shares. This theoretical simulation suggests that the EHR4CR business model appears profitable and sustainable, assuming that the EHR4CR platform would be commercially available at the beginning of Year 1 (i.e. post project), and that EHR4CR solutions would be quickly adopted by clinical research sponsors at project completion, followed by a swift and scalable EHR4CR market penetration across Europe in the subsequent years. This business model simulation is based on the market assumptions validated by the BMI-TF experts at the time of model development, and on the probabilistic sensitivity analyses across all the distribution ranges provided for all parameters.

\section{Discussion}

The widespread adoption of EHRs is accelerating through the richer collection of clinical data[43]. In addition, experts agree that EHRs can help achieve integrated health care, optimise health outcomes, reduce errors, curb costs and improve quality of care $[44,45]$. As patient care moves from in-patient to ambulatory or other fragmented models of service delivery using multiple healthcare providers, the portability, interoperability and timely access to data have become increasingly important $[44,46]$. It is expected that the increasing exploitation of EHRs will facilitate population-based health care models and outcomes research[45]. Data mining research is also growing in the world of data 
integration, health information exchange, decision support systems, and knowledge discovery, and huge investments are being made in this research sector $[44,46]$. However, considerable hurdles must be overcome [47], including privacy and security issues[48], and other practical, technological, economic, political, professional and societal barriers which impede the exploitation of EHR [45, 47]. In particular, patients expect safe and high-quality care, privacy protection, rights of access and correction, and the opportunity to give consent for research uses of their health information [45, 48]. Nonetheless, the vast deployment of EHRs in Europe and the development EHR4CR innovative platform are providing a ground-breaking opportunity to pioneer the research use of EHR health data[22]. As the pharmaceutical industry is remodelling its R\&D platforms to enhance its value chain, reduce costs and improve efficiency [3, 49-53], EHR4CR solutions promise to transform the clinical research landscape by enhancing and speeding up existing clinical research processes. Using a scalable approach, the deployment of EHR-enabled solutions for research will generate new business opportunities with significant growth potential for all stakeholders involved, as well as added value for clinical trial sponsors [52, 53], for the benefit of patients, health systems, and society[2].

\subsection{Creating value}

While public funding is helpful in the development stages, there is a high demand for flexible and service-oriented business models $[5,9,44]$. In order to guide the sustainable exploitation of EHR4CR solutions by accredited service providers, a comprehensive business model was developed by the BMI-TF. As described in the Appendix, the business model proposes that EHR4CR service providers implement specific activities to 
create value. Such activities include developing and maintaining the EHR4CR platform, building the connecting capacity, delivering trustworthy EHR4CR solutions in compliance with data protection and privacy requirements, establishing and growing the customer base, expanding the reach and scope of services over time (including globally), building stakeholder engagement, leveraging research opportunities, and generating evidence-based value assessments. The main resources to be deployed will include IT experts, sales and marketing resources, management and administrative support, and domain-specific experts. Moreover, partnerships will be established with key stakeholders (e.g. the $i H D$, clinical trials' sponsors, data providers, academic leaders, industry, specialised media, etc.) so to build further awareness and advocacy, accelerate the adoption of EHR4CR services, identify new business needs and channels, and develop new solutions. For instance, by promoting the research use of health data, guiding the cohesive development of research platforms, and delivering accreditation and certification programmes ensuring that highest quality requirements and standards are met $[2,21,22]$, the $\dot{i} H D$ will contribute to establishing best practices, building trust, and achieving a sustainable ecosystem driven by innovation and excellence across Europe, and beyond.

\subsection{Delivering value}

The primary customer segments for EHR4CR service providers were defined as clinical trial sponsors (pharmaceutical industry and their designated CROs), and CRUs (academic clinical research centers). In this emerging market, trusted and long-term relationships will be developed by delivering reliable services and meaningful value propositions, building a well-connected EHR4CR community (i.e. a European network of excellence), 
and establishing best practices for the research use of health data. Customer channels will include direct service offerings to the primary customer segments, and indirect reach by engaging and leveraging data providers (hospitals) and EHR/EDC industry networks. Value propositions were thus tailored to address the specific unmet needs of key stakeholders, and where relevant, substantiated with quantitative assessments. In particular, a cost-benefit assessment [52, 53] and a budget impact analysis[54] were carried out from the perspective of primary sponsors of clinical trials, establishing the added value and the financial impact of using EHR4CR solutions compared to current practices. While these assessments were highly conclusive, they are based on validated assumptions, including market readiness in Europe and a swift adoption of EHR4CR solutions at project completion. This evidence of value will continue to be generated (including in real-world conditions) and disseminated broadly in order to build further awareness and strong multi-stakeholder engagement across Europe.

\subsection{Capturing value}

The business model simulation was carried out from the perspective of an EHR4CR service provider, confirming that the exploitation of the EHR4CR platform represents a commercial opportunity for opening new business channels, diversifying an existing business portfolio, building organisational expertise, and capturing business value. As described in the Results Section, the estimated financial outcome is reported for any given EHR4CR service provider, assuming similar operational conditions for all. In order to optimise value and achieve sustainability, EHR4CR service providers will need to develop their respective business plans, as well as the full scope of activities and resources to be deployed in the first year(s) of operation, including their competitive 
service offering, cost structure, revenue streams, pricing schemes, and commercial performance metrics. Moreover, the proposed business model should ideally be managed and revisited periodically in response to evolving markets' needs, emerging business intelligence, competitive activity, etc. This would contribute to engaging the EHR4CR community in establishing best practices in business model innovation and value optimisation.

For achieving its full business potential, the EHR4CR plaform will also have to overcome several threats such as often inadequate and inconsistent clinical documentation within EHR[21]. This will require building awareness and clearly describing to the medical comunity, data providers, EHR/EDC vendors, patients, CROs, and clinical trials sponsors the benefits of enabling the use of EHR health data for research. This would ensure that optimal systems and processes are established in order to collectively improve the quality of health data for research. In some cases, this may require additional investments to upgrade existing IT infrastructures, source data systems, and data collection processes, as well as dedicated efforts for establishing best practices and optimising benefits for all stakeholders.

In addition, the EHR4CR platform will require achieving optimal interoperability across EHR systems in order to offer a seamless and reliable end-to-end user experience. However, the near-universal downscaling of many national eHealth programmes might limit the investments in extending the richness and interoperability of EHR systems, and of the infrastructure to enable them to communicate at a regional or national level. This may have an impact on the costs and efforts required by EHR4CR service providers to link up individual hospitals to the platform, and on the estimated profitability ratio, 
especially in the first years of operation. As a result, it may be necessary to prioritise an affordable first wave of services that limits such costs until the value proposition and business justification for enrichment are evident from early success.

\subsection{Study Limitations}

Regarding study limitations, this business model simulation remains a theoretical demonstration developed in the context of a European project, and does not necessarily reflect real-world commercial conditions. In addition, our model assumes that a commercial-grade version of the platform will be deployed and will be operational at the start of the 5-year period. While the simulation does take into account some maintenance functions, it currently does not include any further investments in R\&D or commercial operations. For this reason, the uncertainty was managed using probabilistic sensitivity analyses so to appropriately reflect the full scope of the underlying assumptions. While our profitability analysis appears conclusive, it assumes that all market uptake objectives set for the EHR4CR scenarios would be achieved within the ranges and timelines forecasted. Although Year 1 profitability ratio may appear overly optimistic by assuming market readiness at the time of launch, this assumption considers that substantial efforts have been deployed throughout this 5-year project in order to build awareness, engage key stakeholders, and prepare the market. This suggests that the profitability forecast would likely be even more achievable for the second year, when the initial market has been established. Nonetheless, the business model simulation uses conservative market penetration estimates in order to reflect a progressive market uptake and a scalable deployment, as planned. Furthermore, simulation models being useful to 
generate quantitative assessments, ours could be revisited in the future, and populated with data generated in real-world conditions (i.e. post-commercialisation). Importantly, the business model simulation having been conducted in a pre-launch context, it does not take into account specific pricing strategies and future commercial offers (e.g. competitive service bundling, discounts, etc.) that may be established by different EHR4CR service providers. Considering that a key feature of multi-sided markets is the innovative pricing strategies they employ (i.e. to attract one group of users, other group of users may be subsidised [55]), competitive pricing will also directly influence the EHR4CR market uptake and profitability margins. Again, it would be interesting to conduct subsequent economic analyses using real-world evidence (i.e. once the EHR4CR solutions are implemented). Such analyses would provide additional evidence to substantiate value propositions to clinical trial sponsors, data providers, and EHR industry.

Despite these limits, and considering the inherent challenges related to the adoption of a new technology, this business model establishes that EHR4CR solutions will create, deliver and optimise value for all stakeholders involved. Because our profitability analysis is situated somewhat in the future, new or disruptive technologies could also influence the clinical research landscape and affect the conclusions of this study. Until then, it will be important that the business model roadmap continues to build the demand for EHR4CR services, demonstrates its value (including in real-world contexts), and leverages stakeholder engagement and dissemination strategies, in Europe and beyond. 


\subsection{Outlook for the future}

Amongst other emerging technologies in the health sector, the EHR4CR platform will transform the clinical research landscape by enabling the re-use of hospital-based EHR patient-level data for research. This study has described the methods used for gathering and analysing multi-source business intelligence towards developing a sustainable business model for the EHR4CR platform, and for assessing its economic sustainability. In this emerging business ecosystem, EHR4CR service providers will be uniquely positioned to deliver trustworthy innovative and value-added solutions in compliance with all audit requirements and policies. Using a scalable approach, they will be empowered to rapidly grow this market and to establish trusted relationships with clinical trial sponsors, as well as best practices with the multi-stakeholder network of excellence enabled by the $i H D$. The adoption of a systematic business model innovation process will allow EHR4CR service providers to regularly update the proposed business model in response to market demands, and to generate added value in a consistent manner. By leveraging new research opportunities, including for generating evidence of value from real-world contexts, EHR4CR service providers will contribute to creating new business opportunities, and to building further sustainability.

For clinical trial sponsors, the EHR4CR platform represents a breakthrough innovation to optimise R\&D value chains, reduce operational costs, add substantial value, and enable the delivery of safe and effective innovative medicines to healthcare faster. For data providers, service providers and the ICT industry, the EHR4CR platform will establish new benchmarks and best practices in advancing today's clinical research, and exploiting new business opportunities and revenue streams. For patients, health authorities, and 
society, EHR4CR will provide revolutionary solutions that will contribute to optimising societal value and health outcomes, in Europe and worldwide.

\section{Conclusions}

The EHR4CR project has demonstrated that a detailed and robust business modelling methodology provides important insights on how the results of an R\&D project should be sustained. The authors have learned that business modelling plays an important, but often undervalued, role in directing the strategic direction of a research endeavour, and should be undertaken in parallel to the research, not towards the end of the project. They believe that research leaders and research funders should more strongly promote the importance of business modelling as a key part of a research methodology and work plan.

\section{Authors Contributions}

All authors have made substantial contributions to this paper. DD, AB, MS, AS, JA, PC, DK, MD, GDM contributed to defining the EHR4CR ecosystem. DD, AB, MS, AS, JA, DK, GDM participated in the business model design. DD, AB defined the assessment methods and conducted the simulation modelling. DD, AS, JA, PC, DK wrote the initial drafts of the paper. DD, AB, MS, AS, JA, PC, DK, MD, GDM edited and revised the manuscript. 


\section{Funding Acknowledgement}

This project has received funding from the European Union Seventh Framework

Programme (FP7/2007-2013) under the Joint Undertaking Grant Agreement n ${ }^{\circ} 115189$ of the Innovative Medicines Initiative (IMI) (http://www.imi.europa.eu), a public-private partnership between the European Commission and the European Federation of Pharmaceutical Industries and Associations (EFPIA). The sole responsibility for the content of this article lies with the authors and does not necessarily reflect the opinion of the European Commission or EFPIA. The European Commission and EFPIA are not responsible for any use that may be made of the information contained therein.

\section{Conflicts of interest statement}

We confirm that there are no known conflicts of interest associated with this publication. DK is founding member of the I HD. DK and MS are members of the Executive board of the I HD. 


\section{Summary Table}

\section{What was already known on the topic}

- Clinical research faces major bottle necks as well as escalating costs

- Clinical trials design is often sub-optimal, leading to costly protocol amendments

- Patients' enrolment in clinical trials is slow and time consuming, leading to important delays

- Study conduct is lengthy and laborious, and the reporting of serious side effects is poor

- EHR represent significant sources of health data for research purposes

\section{What this study added to our knowledge}

- Sustainable business models are needed to optimise the value of new technologies

- A multi-stakeholder value chain contributes to maximising the benefits for all stakeholders

- Meaningful value propositions are key enablers for engaging stakeholders

- Robust business model simulations guide the successful deployment of new technologies

- Real-world value assessments are needed to enrich and strengthen initial value propositions 


\section{REFERENCES}

[1] Sertkaya A, et al., Examination of Clinical Trial Costs and Barriers for Drug Development. July 25, 2014. Easter Research Group Inc.

[2] Kalra D, et al., Case Report from the EHR4CR Project - A European Survey on Electronic Health Records Systems for Clinical Research. iHealth Connections, 2011. 1(2): p. 108113.

[3] Epstein RS, R\&D transformation and value-based innovation. J Comp Eff Res, 2012. 1(1 Suppl): p. 1-2.

[4] Zott C and Amit R, The fit between product market strategy and business model: implications for firm performance. Strategic Management Journal, 2008. 29: p. 1-26.

[5] Chesbrough $\mathrm{H}$ and Rosenbloom RS, The role of the business model in capturing value from innovation: evidence from Xerox Corporation's technology spin-off companies. Industrial and Corporate Change, 2002. 11(3): p. 529-555.

[6] Hedman J and Kalling T, The business model concept: theoretical underpinnings and empirical illustrations. European Journal of Information Systems, 2003(12): p. 49-59.

[7] Amit R and Zott C, Value creation in e-business. Strategic Management Journal, 2001. 22: p. 493-520.

[8] Dubusson-Torbay $\mathrm{M}$, Osterwalder $\mathrm{A}$, and Pigneur $\mathrm{Y}$, E-business model design, classification, and measurements. Thunderbird International Business Review, 2002. 44(1): p. 5-23.

[9] Magretta J, Why business models matter. Harvard Business Review, 2002(May): p. 3-8.

[10] Osterwalder A, Pigneur Y, and Tucci CL, Clarifying business models: origins, present and future of the concept. . Communications of the Association for Information Science, 2005. 16: p. 1-25.

[11] Shafer SM, Smith HJ, and Linder J, The power of business models. Business Horizons, 2005. 48: p. 199-207.

[12] Sheenan NT and Stabell CB, Discovering new business models for knowledge intensive organizations. Strategy and Leadership, 2007. 35: p. 22-29.

[13] Doganova $L$ and Eyquem-Renault $M$, What do business models do? Innovation devices in technology entrepreneurship. Research Policy, 2009(38): p. 1559-1570.

[14] Chesbrough, H., Business model innovation: it's not just about technology anymore. Strategy and Leaderhip 2007. 35: p. 12-17.

[15] Mitchell D and Coles C, The ultimate competitive advantage of continuing business model innovation. Journal of Business Strategy, 2003. 24: p. 15-21.

[16] Anderson B, Johannesson P, and Zdravkovic J, Aligning goals and services through goal and business modeling. Information Systems e-Business Management, 2009. 7: p. 143169.

[17] Yip G, Using strategy to change your business model. Business Strategy Review, 2004. 15(2): p. 17-24.

[18] Zott C and Amit R, Business model design and the performance of entrepreneurial firms. Organization Science 2007. 18: p. 181-189.

[19] Patzelt H, Knyphausen-Aufse D, and Nikol P, Top management teams, business models and performance of biotechnology ventures: an upper echelon perspective. British Journal of Management, 2008. 19: p. 205-21.

[20] Osterwalder A and Pigneur Y, Business Model Generation. 2009, Self-published.

[21] De Moor G, et al., Using electronic health records for clinical research: the case of the EHR4CR project. J Biomed Inform, 2014. 53: p. 162-73. 
[22] Coorevits $P$, et al., Electronic health records: new opportunities for clinical research. J Intern Med, 2013. 274(6): p. 547-60.

[23] Abraham C, Nishihara E, and Akiyama M, Transforming healthcare with information technology in Japan: A review of policy, people and progress. International Journal of Medical Informatics, 2011. 80: p. 157-170.

[24] Rigby M, Ronchi E, and Graham S, Editorial: Evidence for building a smarter health and wellness future - Key messages and collected visions from a Joint OECD and NSF workshop. International Journal of Medical Informatics, 2013. 82: p. 209-219.

[25] Geissbuhler A, Lessons learned implementing a regional health information exchange in Geneva as a pilot for the Swiss national eHealth strategy. International Journal of Medical Informatics, 2013. 82: p. e118-e124.

[26] Nikayin F, De Reuver M, and Itälä T, Collective action for a common service platform for independent living services. International Journal of Medical Informatics, 2013. 82: p. 922-939.

[27] Stroetmann KA, Achieving the intergrated and smart health and wellbeing paradigm: $A$ call for policy research and action on governance and business models. International Journal of Medical Informatics, 2013. 82: p. e20-e37.

[28] Mintzberg H and Quinn JB, The Strategy Process: Concepts, Contexts, Cases. 1996: Prentice Hall.

[29] McNamara C, All About Strategic Planning. Adapted from Field Guide to nonprofit Strategic Palnning and Facilitation.: Authenticity Consulting LLC.

[30] Hill C and Jones G, Strategic Management: An Integrated Approach. 8th Revised Edition ed. 2008: Mason OH: South-Western Educational Publishing.

[31] Arline K, What Is a Vision Statement? Business News Daily, 2014(December).

[32] Collins JC and Porras JI, Building you company's vision. Harvard Business Review, 1996(Sept-Oct).

[33] McNamara C, Basics of Developing Mission, Vision and Values Statements. Adapted from the Field Guide to Nonprofit Strategic Planning and Facilitation.: Authenticity Consulting LLC.

[34] Bart CK, Industrial firms and the power of mission. Industrial Marketing Management, 1997. 26(4): p. 371-383.

[35] Adner R and Kapoor R, Value creation in innovation ecosystems: how the structure of technological interdependence affects firm performance in new technology generations. Strategic Management Journal, 2010. 31(3): p. 306-333.

[36] Weinstein M, Recent developments in decision-analytic modelling for economic evaluation. Pharmacoeconomics, 2006. 24(11): p. 1043-1053.

[37] Kalra D, et al., The European Institute for Innovation through Health Data. Learn Health Sys, 2016: p. 1-8.

[38] Evans DS, Managing the Maze of Multisided Markets. Strategy + Business, 2003(32): p. 1-5.

[39] Hagiu A and Wright J, Multi-Sided Platforms. Harvard Business School Working Knowledge, 2011(Working Paper 12-024).

[40] Timmers P, European Commission, and Directorate General III, Business Models for Electronic Markets. Electronic Markets, 1998. 8(2): p. 3-8.

[41] Eisenmann T, Parker G, and Van Alstyne M, Strategies for Two-Sided Markets. Harvard Business Review, 2006.

[42] EudraCT, European Clinical Trials Database. European Medicine Agency, 2012. 
[43] Geissbuhler A, et al., Trustworthy reuse of health data: A transnational perspective. International Journal of Medical Informatics, 2013. 82: p. 1-9.

[44] Higgins JK, Electronic Health Records: Big Business, and Getting Bigger. TechNewsWorld Best of ECT News. http://www.crmbuyer.com/story/69994.html, 2010(May 14).

[45] Gunter TD and Terry NP, The emergence of national electronic health record architectures in the United States and Australia: models, costs, and questions. J Med Internet Res, 2005. 7(1): p. e3.

[46] Jensen, P., L. Jensen, and S. Brunak, Mining electronic health records: towards better research applications and clinical care. Nature Reviews Genetics, 2012. May 2.

[47] Laurie G, et al., On moving targets and magic bullets: Can the UK lead the way with responsible data linkage for health research? International Journal of Medical Informatics, 2015. 84: p. 933-940.

[48] van der Linden $\mathrm{H}$, et al., Inter-organizational future proof EHER systems. A review of the security and privacy related issues. International Journal of Medical Informatics, 2009. 78: p. 141-160.

[49] Epstein, R., Sidorov, J, Lehner, JP, Salimi, T., Integrating scientific and real-world evidence within and beyond the drug development process. Journal of Comparative Effectiveness Research, 2012. 1(Suppl. 1): p. 9-13.

[50] Lehner JP, Epstein RS, and Salimi T, Integrating new approaches for clinical development: translational research and relative effectiveness. J Comp Eff Res, 2012. 1(1 Suppl): p. 15-21.

[51] Salimi T, Lehner JP, and Epstein RS, A framework for pharmaceutical value-based innovations. Journal of Comparative Effectiveness Research, 2012. 1(Suppl. 1): p. 3-7.

[52] Beresniak A, et al., Cost-Benefit Assessment of the Electronic Health Records for Clinical Research (EHR4CR) European Project. Value in Health, 2014. 17: p. A630.

[53] Beresniak A, et al., Cost-benefit assessment of using electronic health records data for clinical research versus current practices: Contribution of the Electronic Health Records for Clinical Research (EHR4CR) European Project. Contemporary Clinical Trials, 2016. 46: p. 85-91.

[54] Dupont D, et al., Assessing the Financial Impact of Reusing Electronic Health Records Data for Clinical Research: Results from the EHR4CR European Project J Health Med Informat, 2016. 7(3).

[55] Parker G and Van Alstyne MW, Two-Sided Network Effects: A Theory of Information Product Design. Management Science, 2005. 51(10): p. 494-504. 


\section{Appendix}

Online Appendix: Business model components using the perspective of EHR4CR service providers $^{\S}$

\begin{tabular}{|c|c|}
\hline $\begin{array}{ll}\text { 1. } & \text { Primary } \\
\text { Customers }\end{array}$ & - $\quad$ Clinical Trial Sponsors (pharma, CROs, academic clinical research units) \\
\hline $\begin{array}{ll}\text { 2. } & \text { Customer } \\
\text { Relationships }\end{array}$ & $\begin{array}{l}\text { Establish a dynamic EHR4CR community and best practices } \\
\text { - } \quad \text { Build and support a European network of Excellence } \\
\text { - }\end{array}$ \\
\hline $\begin{array}{ll}\text { 3. } & \text { Customer } \\
\text { Interface }\end{array}$ & $\begin{array}{ll}\text { - } & \text { Direct reach and stakeholder engagement } \\
\text { - Indirect (leverage EHR/EDC and hospital network) }\end{array}$ \\
\hline $\begin{array}{ll}\text { 4. } & \text { Value } \\
& \text { Propositions }\end{array}$ & $\begin{array}{l}\text { Deliver trustworthy EHR4CR value-added services and customised value } \\
\text { propositions based on evidence of EHR4CR benefits, value creation and } \\
\text { optimisation }\end{array}$ \\
\hline 5. Main Activities & $\begin{array}{l}\text { - } \text { Develop and maintain an advanced technology platform } \\
\text { - } \text { Build and grow the customer base } \\
\text { - } \text { Build stakeholder engagement and advocacy } \\
\text { - } \quad \text { Leverage research opportunities } \\
\text { Conduct evidence-based value assessment }\end{array}$ \\
\hline 6. Main Resources & $\begin{array}{ll}\text { - } & \text { IT experts } \\
\text { - } & \text { Sales \& Marketing } \\
\text { - } & \text { Management and Administrative Support } \\
\text { Domain-Specific Experts }\end{array}$ \\
\hline $\begin{array}{l}\text { 7. Partnerships } \\
\text { /Alliances }\end{array}$ & 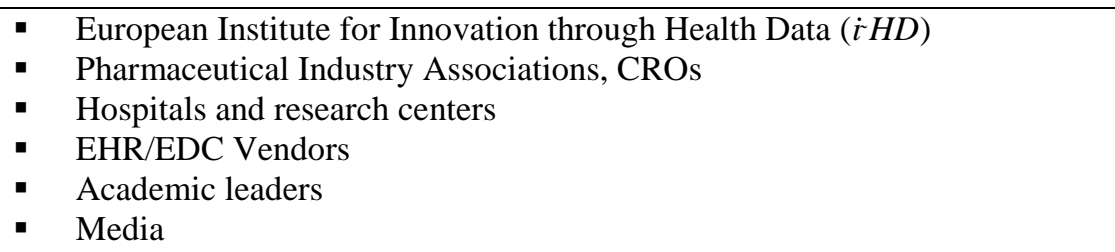 \\
\hline 8. $\quad$ Expenses & $\begin{array}{ll} & \text { Operational expenses } \\
\text { - } & \text { Work contracted out (domain-specific experts) } \\
& \text { Licensing and data access fees }\end{array}$ \\
\hline 9. Revenues & $\begin{array}{ll}\text { - } & \text { Annual subscriptions (connecting fees) } \\
\text { EHR4CR fees for service } \\
\text { Potential consulting fees (long term) }\end{array}$ \\
\hline
\end{tabular}

